\title{
Post Mid-Staffordshire Inquiries Reaction, in and about the National Health Service (NHS), England. The Missing Pieces: Organizational, Care and Virtue Ethics Perspectives
}

\author{
Albert Coleman \\ Southern Health NHS Foundation Trust, Hampshire, UK \\ Email: albert.coleman@gmail.com \\ Received 18 June 2014; revised 17 July 2014; accepted 16 August 2014 \\ Copyright (C) 2014 by author and Scientific Research Publishing Inc. \\ This work is licensed under the Creative Commons Attribution International License (CC BY). \\ http://creativecommons.org/licenses/by/4.0/

(c) (i) Open Access

\begin{abstract}
The release of the Mid Staffordshire hospital report otherwise called the Francis report once again ignited the debate about the issue of abuse of especially vulnerable patients, while navigating the care pathway as inpatients in hospitals; within the National health service (NHS), England. Once more the official reaction from the NHS directorate is more "standards" to monitor failed standards in patient care. Of interest in the official responses so far, are the unheard voices addressing the issue of healthcare and organizational ethics concerns that need revisiting. This article seeks to revisit practice, systems and care issues leading to incidents of the type of the Staffordshire abuses, and the important but yet unheralded place of organizational and care ethics in helping to curb such abuses from re-occurring.
\end{abstract}

Keywords

Health Professionals, Quality of Care, Rights, Health Care Ethics

\section{Introduction}

Following the publication of the final Francis report [1] into reported mismanagement of patients admitted to Mid Staffordshire hospital, there has been a mix of reactions from different sections of the British society. The mixed reactions come from politicians, media spin masters, NHS executives, NHS line staff including doctors 
and nurses, patient advocacy groups and the lay public [2]-[6]. Most of the reaction has been an expression of dismay and disgust at what reportedly might have been sometimes inhumane treatment meted out to the particular patients, especially elderly patients on admission to the particular hospital. It appears that the pervasive sentiment is that certain persons, mostly health care professionals (HCPs) knowingly may have been part of, or turned a blind eye to these troubling allegations, when they supposedly happened.

In some printed media these people have been branded as "bad persons," with a call for heads to start rolling, and others calling for criminal prosecutions to be handed down [2] [4]. Almost a similar type of reaction albeit not as vocal, was heard post publication of the Alder Hey hospital report (Redfinn report) [7], Bristol [8] and post Shipman [9]. With the exception of the late Dr. Shipman who in hindsight may have had sociopathic tendencies; I would question any presupposition that most other health professionals involved in or circumstantially associated with the Alder hey and mid Staffordshire scandals, were necessarily "bad or bad intentioned".

Considering the internal climate of the current NHS, there are in my opinion questions of an organisational or systemic type, that underlies the behaviours (individual and systemic) that lead to these scandals, as other authors have observed [1]. Surprisingly following the release of the foregoing reports following the respective scandals, what seems to happen and actually happened, was the release by the governmental and then the NHS executive directorate of further red taped guidelines, to top up the pre-existing guidelines that set the stage for the scandals [5].

\section{Challenges of Current Healthcare Practice Paradigms}

The mandate setting up the NHS in the 1945 was meant to ensure that the British populace had a health service, that provided access and coverage to it citizens along the principles developed in the 1942 Beveridge report [10] and the national health service act (NHS) act, (Bevan) [11] of 1946. Post Beveridge and Bevan, with the changing health care delivery climate the practise of health care delivery has gradually shifted from a patient care centred model to an evidence medicine based [12] and care pathway model [13]. Arising from the evidence based model (EBM) of care delivery meant to inform knowledge based medical practice, has emerged the use of EBM to economically determine or rationalise care delivery with sometimes unethical outcomes [14]. Since the move in the NHS towards efficiency savings, initially introduced as a cut management measure, the process has morphed slowly into what is clinically considered "evidence backed" mode of operation, under the guise of quality, innovation, protection and prevention (QIPP) [15]. Of worry though for various HCPs within the NHS, is the impact of NHS efficiency savings strategy on patient care quality [16]. Historically the proponents of EBM from McMaster university school of medicine, Canada [17], meant to teach the medical fraternity how to properly read published "scientific" papers. The off shot of this was the growth of evidenced based treatment outcome guidelines. These guidelines eventually will inform medical practitioners as to what a certain expert's panel, having analysed the available peer reviewed scientific evidence; thought was good practice for management of particular illnesses. With the cuts in NHS budgets, target-based health care policies [18] seem to be in some cases the "new NHS" policy guidance, disguised sometimes under the term of "governance". Unfortunately in the quest to achieve these NHS targets and outcome driven push, the fall guy becomes the patient. QIPP related staff cuts to achieve efficiency savings has led in some instances to low staff to patient ratio, due to budgetary and financial constraints. This situation puts enormous pressure on HCP time and availability. This then affects their capacity to appropriately deliver the required individualised patient centred care required, especially around feeding and personal care. This on a systemic scale may lead to the situation of "systemic failures" as alluded to in the Francis report [6].

Systemic impediments/failures of these types can contribute to moral distress, among HCP [19]. The scenarios in this paragraph, simplistic as they seem, is not infrequent in healthcare settings. Especially elderly care inpatient settings in the UK [20]. Granted this is not the pervasive scenario, it is not uncommon either.

\section{Synopsis of Determinants of Health (Care)}

Factors determining the health of individuals/population groups as proposed by some authors are individual/population genetics, behavioural determinants, healthcare systems and environmental determinants [21]. Determinants of an ideal pathway are considered by some, to include the structure, processes and outcomes [22]. Expanding a bit on these, the right organizational set-up, staff and mission constitute the structure, the right way of doing things, constitute the processes and the right, desired results constitute the outcome [22]. Hence with 
"control" of the other three determinants (genetic, behavioural and environmental) mentioned earlier, the organizational determinant on which the structure, processes and outcomes are built on, looms large as a very influencing determinant of health and healthcare delivery. In considering health care systems as an important health determinant factor, with the current NHS targets driven orientation, and the associated pressure on HCP in the NHS, the NHS may be placing their health determinant role under threat. These factors may have potentially contributed to the systemic failures (among others), of the type tied to the Mid-Staffordshire scandal.

\section{Contemporary Healthcare Delivery, and Care and Organizational Ethics}

The consequence of the challenges in delivery of contemporary healthcare to patients in the instances portrayed in the preceding paragraph presents challenges. These challenges are pronounced in the geriatric patients with ambivalent or poor decision making capacity, those one would consider the vulnerable, vulnerable. If one were to view this group within the limits of the determinants of healthcare delivery, and the moral and normative expectations of care delivery; this group appropriately fit into the group of "vulnerable falling through the care web" [23].

The care ethic paradigm approach in managing these vulnerable patients, is for the health care giver to 1) recognise the vulnerable state of such an individual patient 2) determine that such vulnerable patient needs to be giving care 3) the care-giver then gives the care deemed appropriate and 4) the care given is reciprocated by the recipient, in this case the patient; with an acknowledgement [23]. This paradigm is clearly different to the four principles ethics paradigm of autonomy, beneficence, non-malfeasance and justice [24], popular in general among Anglo-American physicians and medical school trainees.

Organizational ethics as it applies to health care organizations refers to institutional core moral underpinnings of operation, which is shared by the management and stakeholder. The ethics of an organisation stems from a premise that organizations have a "culture", and part of the culture is the ethical underpinnings of the particular organization. This culture of which ethics is a component is thought of as a shared belief of the organizations directorate, management and stakeholders. This may be expressed or surmised in an organizational mission statement. This organizational cultural paradigm is of a fiduciary nature, against a background of the principles of Stakeholder theory; a concept of business management [25]. The very nature of health care organizations (HCO), emphasising the delivery of care to patients (stakeholders), often times vulnerable as a consequences of their ill health; places HCOs' on a “different corporate” level, in my opinion. Specifically for HCOs' there should be an acceptance of a prima facie type, of the fundamental "normative" basis of stakeholder theory, in the relation of the organization with the patient stakeholder [26]. This will be the underlying moral or ethical culture of HCO, otherwise called the organizational culture.

\section{Discussion}

In England and Wales the Care Quality Commission (CQC) defines its work through "the monitoring of standards in regulating health and social care". The standards are supposed to relate to the 28 regulations in the legislation governing their work. These standards (twenty eight of them) are divided into the sixteen "essential standards" related to the quality and safety of care, and the other twelve standards relate to the day-to-day management of a service [27]. The standards "are linked to outcomes that health and social service clients are expected to receive as a result of the care they receive" [27]. In the healthcare "corporate setting" of the NHS, the respective professionals i.e. doctors, nurses, physiotherapists etc., are individually regulated and or licensed through their registration with their various professional regulatory bodies; i.e. general medical bodies (GMC), nurses and midwives council (NMC) etc.

However except for individual professional related gross misconduct when their respective employers or individuals can refer HCPs to these bodies. Beyond these professional oversight, conformity to the NHS corporate demands 1 will hypothesize may be what is most noticeable.

Conformity to the NHS corporate managerial practices thus ends up shaping how its employee's work, in delivering service to the patient stakeholders. Here in (again in my opinion), lies the dangers associated with incidents of the like, as what happened in Mid Staffordshire. In a climate of emphasis on outcomes, targets, waiting times, length of hospital stays, budgetary constraints, rationalization etc., corners may be cut overtly or covertly. In this climate the corporate taskmasters tasked with enforcing "standards" get to work on line staff to conform. This in my opinion contributed to the "problem with systems", referred to in the Francis report [1]. It is in this 
pressure climate that in some instances corporate psychopaths or "snakes in suit" [28] [29], masquerading as "strong team leaders" get the opportunity to operate. These "leaders" in the name of meeting standards and ensuring outcomes, are seen in corporate organisations of the like of the NHS. They may go any length using line staff, as a means for their own ends. Line staff in trying to meet the expectations of management taskmasters, may then conform to dictates of NHS managerial guidance, at all costs. In the healthcare sector this potentially translates into patient stakeholders being "numbers" in the whole care pathway. In such circumstances compassion and care cannot be easily translated into cost savings, under the current NHS climate of finance rationalization. Patients stake holders, especially the elderly vulnerable may stand out as losers, as the McDonaldization of healthcare [30] goes ahead full steam. In this climate some HCPs may get stuck at the grade 3 to 4 of the ethical behaviour scale [31], where at its best conformity to regulations of governance, becomes foremost on their mind; compared to upholding ethical principles. A situation that could lead to moral distress for some HCPs [19] [32]. This is fertile ground for incidents of the like of the "Mid Staffordshire" scandal.

The only corporate culture or climate able to save such a situation from getting out of hand in my opinion, is not more "governance" edicts or pronouncements as has happened in the aftermath of the Mid Staffordshire scandals [6]. Rather the recognition that there is a need for specific back to basics normative ethics based frameworks, that actually underpins the practice of healthcare professionals and healthcare organisations. Unless care and organizational ethics, along with virtue ethics, are firmly entrenched in the day to day professional and organizational activities of HCPs and HC organizations within the NHS, no amount of governance rules or outcome-based measures will achieve this. It is no surprise that in the United States of America, (USA), the Joint Accreditation of Healthcare organizations (JACHO), the equivalent body of CQC in the USA, found it necessary to incorporate in their mandate and governance legislation as far back as 1995, a new "accreditation standard" [33] [34]. This standard is in the "Patient rights and Organizational Ethics" chapter requiring hospitals "operate according to a code of ethical behaviour" [34]. This statutory requirement imposes on healthcare corporate organizations within the limits of the legal code, not to keep their eyes off the ethics ball; even in the pursuit of economic gains.

\section{Conclusions}

In the aftermath of the release of the second Francis report on the Mid Staffordshire hospital scandal, all one can hear from the general public, HCPs, the NHS executive and government officials, have been calls "for action". On the part of the government and NHS executives, their response to the "action" call, was to roll out a new wave of directives to ensure adherence to pre-existing standards. In addition these new standards are supposed to ensure hopefully, non-recurrence and prevention of future Mid Staffordshire-like scandals. An apparent silence however, is the absence of any comment or appeal to reminding and ensuring the upholding of healthcare ethics practice, on the part of health care organizations and HCPs. I think stems from the inculcation of outcome driven as opposed to care ethics driving practice, in contemporary medical and nursing practices. In this instance difficult to codify concepts like vulnerability, compassion, dignity, virtue, person-centeredness, care ethics etc., necessary to enhance upholding of organizational and individual ethical practices, may get lost in translation. These "thick concepts" of healthcare as opposed to the easily measured "thin concepts" of time-line, governance, outcomes, etc., lead to the McDonalization of healthcare practice [30]. It marks a shift from HCPs engaging human persons, to one of engaging patients as health care market commodities.

The CQC in the United Kingdom, could look towards the equivalent organization in the USA, JACHO, and incorporate in their "standards" by taking a leaf from their "Patients rights and organizational ethics standards requirement." In the presence of such a code tasking the employing HC corporate body to have a culture of ethical practice, HCP as individuals will directly and indirectly be called on to "up" their individual professional practices. This will go a long way to enforce the individual mandated standard of ethical practice, that respective HCP bodies demand from their individual practitioners, in the day-to-day practice of their respective professions. A thought of how HCPs go about their day-to-day vocation is whether they are conventionalist or ethical principled in terms of application of Kolberg's theory of cognitive development, within the context of the ethical behaviour test as applied to HCPs. Some authors think on the ethical behaviour test most nurses will fall at the stage 4 or below grading [31]. I do not think it applies only to nurses. I think the dilemma applies to a good number of physicians too. I say this because HCPs being seen as conventionalist on the ethical behaviour scale/test, may think it a safe position to be; in that they adhering to "convention", or guidelines. Otherwise put, staying within the delineation of NHS managerial directives, sometimes disguised as "governance; rather than 
"rocking the boat" to use ethical based normative principles (in tandem with EBM guidance), to navigate complex medical cases. Considering HC ethical behaviour, practising along the stage 5 to 6 on the ethical behaviour scale/test, draws not only on care ethics principles, but equally on organizational and virtue ethics, even in tandem with EBM.

Of note is that if the NHS directorate is really intent on ensuring that the patients it is responsible for are cared for along the lines of the tenets of dignity, care ethics, virtue ethics etc., then there is still some hope. This is because evidences from some centres have indicated that HCPs can be re-sensitised to the themes of care and care ethics and re-oriented to the principles of empathy, through participation in an experiential immersion of empathy learning of care ethics and caring [35] [36]. This experience of a reflective nature, was one I would term a "reflective experience of an immersion type", which repeated over time, may prime HCPs to ethically reflect on their care practices. Some may associate care ethics to the call for "compassionate" care. The two have similar goals, but are not the same. More so, considering the recent declared opinion of an ethicist that one does not need compassion to give good and effective medical care [37]. In my opinion good and effective medical (healthcare) practice is a combination of EBM and care, virtue and organizational ethics. These elements cannot follow different pathways in healthcare. Post the Francis report, some authors have argued for legislating HCP behaviour in order to ensure caring and safe patient care practices [38]. This in my opinion is a statutory based consequentialist approach that defeats the "special" nature of health care practice, and ethos of first "doing no harm", not as a Hippocratic oath-like dictate, but rather in addition, as a Kantian categorical imperative type. Finally I will argue that HCPs and HCOs including the NHS, have to be always aware that our ethical duty of care may even supersede the expected Kantian deontological duty of a categorical imperative. This is because "duty" to the "vulnerable" sick coming to us for their care, assumes more than a rational role. Care towards the vulnerable patient as per care ethics framework on the other hand encompasses more than the rational mind, it is a combination of the rational self and the emotional self, collectively responding to the vulnerable sick [39].

This care can be considered as incorporating the "thou and I" Levinisian ideals of care for the suffering other [40]. In closing I wish to remind NHS HCPs of the "socratic" analogy [41], that our vocational "technical" practice in the delivery of healthcare to our patients is not worth doing, unless the tenets of organizational, care and virtue ethics is inculcated, alongside EBM medicine and care pathway based healthcare practice. This view is not an attack on EBM or care-pathways, but rather an acknowledgement of the inevitable co-existence of EBM/ care-pathways and care, organizational and virtue ethics, in ensuring our vulnerable sick do not fall through the "web of vulnerability" [22]. Only that will hopefully stop another Mid Staffordshire from re-occurring.

\section{Acknowledgements}

The opinions expressed are those of the author, and not that of his affiliated institution.

\section{Competing Interest}

None declared.

\section{Funding}

This work was not funded or supported directly or indirectly by any funding body.

\section{References}

[1] Francis, R. (2013) The Stationary Office (TSO), London. Report of the Mid Staffordshire NHS Foundation Trust Public Inquiry. Executive Summary. The Stationary Office.

[2] Holmes, D. (2013) Mid Staffordshire Scandal Highlights NHS Cultural Crisis. The Lancet, 381, 521-522. http://dx.doi.org/10.1016/S0140-6736(13)60264-0

[3] Adams, S. (2013) Mid Staffs Inquiry. Failing NHS Managers Should Be Sacked. www.telegraph.co.uk/health/healthnews/9845668/Mid-Staff-inquiry-Failing-NHS-managers-must-be-punished.html

[4] The Sunday Telegraph (2013) Health. Three Senior Doctors Face GMC Hearings over Stafford Hospital Scandal. http://www.telegraph.co.uk/health/heal-our-hospitals/9919493/Three-senior-doctors-face-GMC-over-Stafford-Hospital -scandal.html

[5] Kirkup, J. (2013) Mid Staffs: Criminal Investigations Launched into Care Failings. Daily Telegraph Online. 
http://www.telegraph.co.uk/health/9987312/Mid-Staffs-criminal-investigation-launched-into-care-failings.html

[6] National Health Service (NHS) (2013) Commissioning Board. Report of the Mid Staffordshire NHS Foundation Hospital Trust Public Inquiry. Board Paper: NHSCB28021.

[7] (2000) The Royal Liverpool Children's Inquiry Report.

[8] (2001) Learning from Bristol. The Report of the Public Inquiry into Children's Heart Surgery at the Bristol Royal Infirmary. 1984-1995. CM 5207(1).

[9] Secretary of State for Health. Safeguarding Patients (2007) The Government's Response to the Shipman Inquiries Fifth Report and to the Recommendations of the Ayling, Neale, and Kerr/Haslam Inquiries. The Stationary Office, London.

[10] Beveridge, W. (1942) Social Insurance and Allied Report. Presented to Parliament (The Beveridge Report). CMND 6404.

[11] National Health Service Act (1946) Her Majesty’s Stationary Office. London. http://old.post-gazette.com/pg/pdf/201004/2010_national-health-service-book_01.pdf http://old.post-gazette.com/pg/pdf/201004/2010_national-health-service-book_02.pdf http://old.post-gazette.com/pg/pdf/201004/2010_national-health-service-book_03.pdf

[12] Shortell, S.M., Rundall, T.G. and Hsu, J. (2007) Improving Patient Care by Linking Evidence Based Medicine and Evidence-Based Management. JAMA, 298, 673-676. http://dx.doi.org/10.1001/jama.298.6.673

[13] Rotter, T., Kinsman, L., James, E.L., Machotta, A., Gothe, H., Willis, J., Snow, P. and Kugler, J. (2010) Clinical Pathways: Effects on Professional Practice, Patient Outcomes, Length of Stay and Hospital Costs (Review). The Chochrane Collaboration. The Chochrane Library, Issue 7. John Wiley \& Sons Ltd., Hoboken.

[14] Mykhalovskiy, E. and Weir, L. (2004) The Problem of Evidence Based Medicine: Directions for Social Scientists. Social Science and Medicine, 59, 1059-1069.

[15] Brocklehurst, P., Jones, C. and Tickle, M. (2011) QIPP: Cutting Budgets or Working Smarter. British Dental Journal, 210, 369-373. http://dx.doi.org/10.1038/sj.bdj.2011.286

[16] Klein, R. (2006) The Troubled Transformation of Britain's National Health Service. The New England Journal of Medicine, 355, 409-415. http://dx.doi.org/10.1056/NEJMhpr062747

[17] Guyatt, G. (2008) Users Guide to the Medical Literature: A Manual for Evidence Based Clinical Practice. 2nd Edition.

[18] Hood, C. (2006) Gaming in Target World: The Targets Approach to Managing British Public Services. 515-521.

[19] Schulter, J., Winch, S., Holzhanser, K. and Henderson, A. (2008) Nurses’ Moral Sensitivity and Hospital Ethical Climate: A Literature Review. Nursing Ethics, 15, 304-321. http://dx.doi.org/10.1177/0969733007088357

[20] Care Quality Commission (2011) Dignity and Nutrition Inspection Programme. National Overview.

[21] Blum, H.L. (1981) Planning for Health. Generics for the Eighties. Human Sciences Press, New York.

[22] Donabedian, A. (1988) The Quality of Care. How Can It Be Assessed? JAMA, 260, 1743-1748. http://dx.doi.org/10.1001/jama.1988.03410120089033

[23] Tronto, J. (2001) An Ethic of Care. In: Holstein, M. and Mitzen, P., Eds., Ethics in Community-Based Elder Care, Springer Publishing, New York, 60-68.

[24] Beauchamp, T.L. and Childress, J.F. (2009) Principles of Medical Ethics. 6th Edition, Oxford University Press, New York.

[25] Donaldson, T. and Preston, L.E. (1995) The Stakeholder Theory of the Corporation: Concepts, Evidence and Implications. Academy of Management Review, 20, 65-91.

[26] American Medical Association (2000) Organizational Ethics in Health Care. Institute of Ethics. American Medical Association, Chicago.

[27] Care Quality Commission (CQC) (2008) Guidance about Compliance, Essentials Standards of Quality and Safety. What Providers Should Do to Comply with the Section 20 Regulations of the Health and Social Care Act. CQC, London.

[28] Babiak, P., Neumann, C.S. and Hare, R. (2010) Corporate Psychopathy: Talking the Walk. Behavioral Sciences \& the Law, 28, 174-193.

[29] Babiak, P. and Hare, R.D. (2007) Snakes in Suits. When Psychopaths Go to Work. Harper, New York.

[30] Ritzer, G. (2008) The McDonalization of Society. Pine Forge Press, Thousand Oaks.

[31] De Casterlé, B.D., Izumi, S., Nelda, S., Denhaerynck, G. and Denhaerynck, K. (2008) Nurses’ Responses to Dilemma's in Nursing Practices: Meta-Analysis. Journal of Advanced Nursing, 63, 540-549. http://dx.doi.org/10.1111/j.1365-2648.2008.04702.x 
[32] Pauly, B.M., Varcoe, C. and Storch, J. (2012) Framing the Issues: Moral Distress in Health Care. HEC Forum, 24, 1-11. http://dx.doi.org/10.1007/s10730-012-9176-y

[33] Zoubul, C. (2009) Health Care Institutional Ethics: Broader than Clinical Ethics. In: Morrison, E.E., Ed., Health Care Ethics, 2nd Edition, Jones and Bartlett, Sudbury.

[34] Joint Commission on Accreditation of Healthcare Organizations (1996) Accreditation Manual for Hospitals. Vol. 1. Oakbrook Terrace. Joint Commission on Accreditation of Healthcare Organizations, Chicago, 44-45.

[35] Vanlaere, L., Coucke, T. and Gastmans, C. (2010) Experiential Learning of Empathy in a Care-Ethics Lab. Nursing Ethics, 17, 325-326. http://dx.doi.org/10.1177/0969733010361440

[36] Harrison, D. (2012) The sTIMUL Project: Putting Yourself in the Patient's Shoes. British Journal of Healthcare Assistants, 6, 546-549.

[37] Smajdor, A. (2013) Reification and Compassion in Medicine. A Tale of Two Systems. Clinical Ethics, 8, 111-118. http://dx.doi.org/10.1177/1477750913502620

[38] Newdick, C. and Danbury, C. (2013) Culture, Compassion and Clinical Neglect: Probity in the NHS after Mid Staffordshire. Journal of Medical Ethics, Published Online. http://dx.doi.org/10.1136/medethics-2012-101048

[39] Miller, S. (2005) A Kantian Ethic of Care. In: Andrews, B.S., Keller, J. and Schwartzman, L.H., Eds., Feminist Interventions in Ethics and Politics. Feminists Theory and Social Theory, Rowman \& Littlefield, Lanham, 111-130.

[40] Diedrich, W.W., Burggraeve, R. and Gastmans, C. (2003) Towards a Levinasian Care Ethics: A Dialogue between the Thoughts of Joan Tronto and Emmanuel Levinas. Ethical Perspectives. Journal of the European Ethics Network, 13, 33-61.

[41] Socrates (1997) In Plato Dialogues. Apology 37e-38a. Bolchazy-Carducci Publishers, Mundelein. 
Scientific Research Publishing (SCIRP) is one of the largest Open Access journal publishers. It is currently publishing more than 200 open access, online, peer-reviewed journals covering a wide range of academic disciplines. SCIRP serves the worldwide academic communities and contributes to the progress and application of science with its publication.

Other selected journals from SCIRP are listed as below. Submit your manuscript to us via either submit@scirp.org or Online Submission Portal.
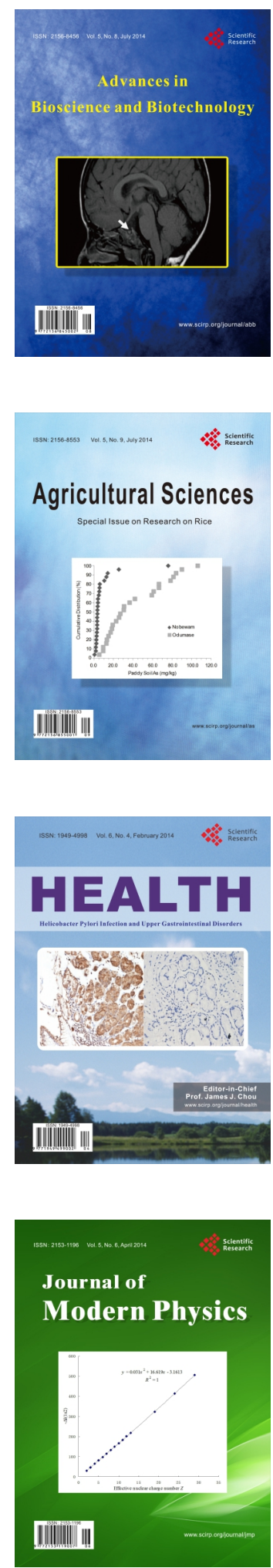
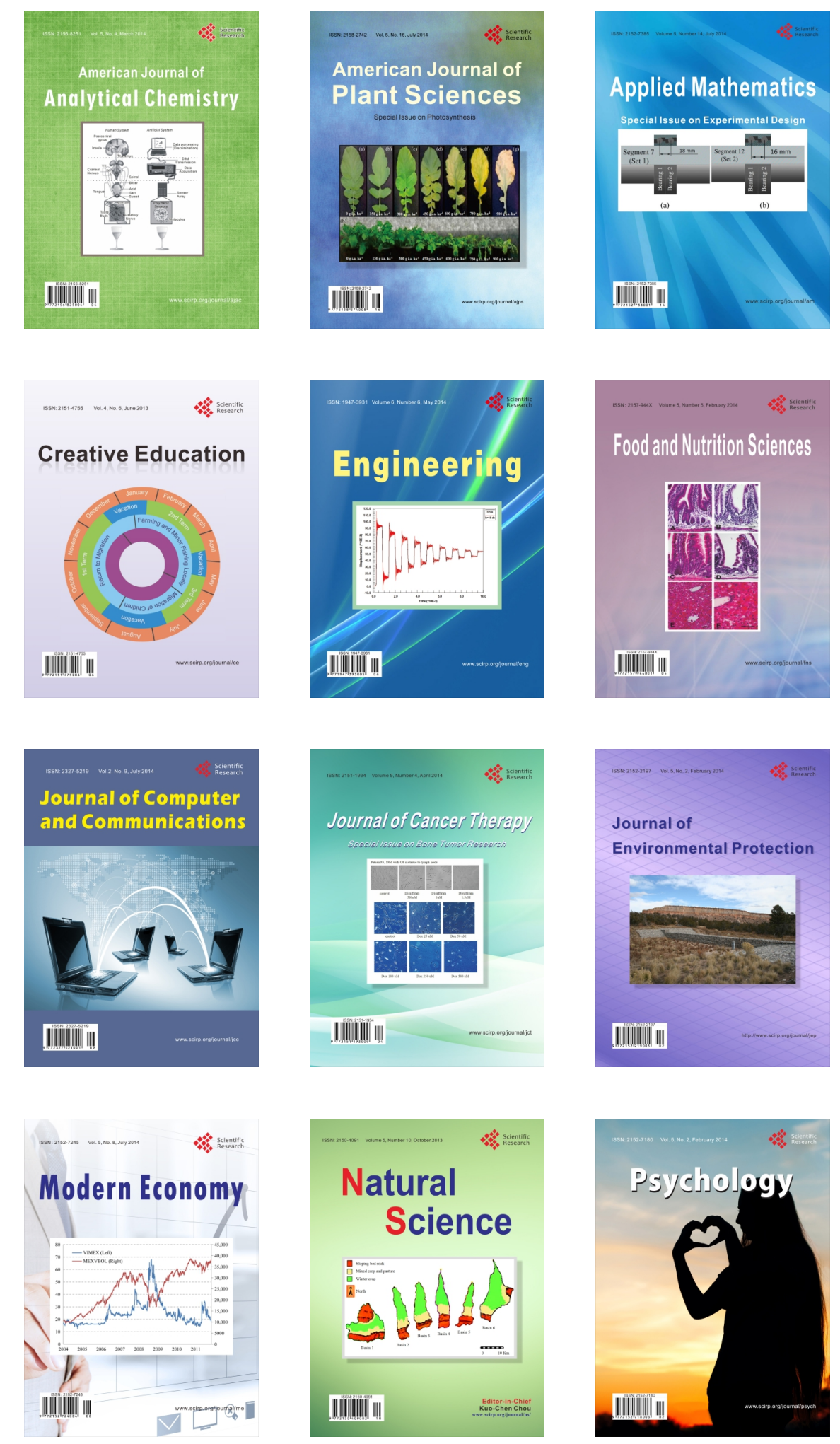